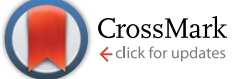

Cite this: RSC Adv., 2017, 7, 3741

Received 10th October 2016 Accepted 6th November 2016

DOI: 10.1039/c6ra24985j

www.rsc.org/advances

\section{Zinc triflate-mediated cyclopropanation of oxindoles with vinyl diphenyl sulfonium triflate: a mild reaction with broad functional group compatibility $\dagger$}

\author{
Mingwei Zhou, ${ }^{\mathrm{ab}}$ Ke En, ${ }^{\mathrm{a}}$ Yimin Hu, ${ }^{\star b}{ }^{\mathrm{b}}$ Yufang $\mathrm{Xu},{ }^{\mathrm{a}}$ Hong C. Shen ${ }^{\mathrm{b}}$ and Xuhong Qian ${ }^{\star a}$
}

The first use of zinc triflate for the cyclopropanation of unprotected oxindoles with vinyl diphenyl sulfonium triflate salt is reported. The reaction proceeded under ambient conditions and consistently provided high yields with broad functional group tolerability. The utility for the late-stage functionalization (LSF) of complex molecules is demonstrated.

Oxindole is a common motif in numerous molecules of great biological and medicinal interest (Fig. 1). Functionalization at the 3-position of oxindoles is a key lead derivatization strategy in medicinal chemistry. In particular, spirooxindoles have demonstrated many applications in drug discovery. ${ }^{1}$ Specifically, spirocyclopropyl oxindoles (Fig. 1: compound 4, 5, and 6) are important because such designs in drug discovery could introduce potentially favorable conformational restraint with marginal addition of molecular weight and lipophilicity. In the
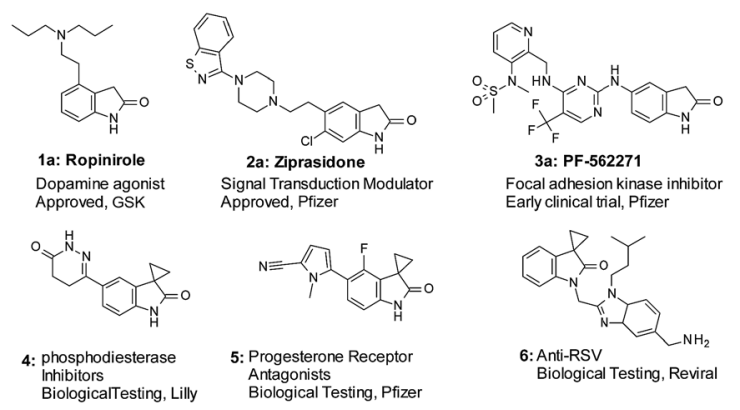

Fig. 1 Oxindoles and spirocyclopropyl oxindoles of medicinal interests.

\footnotetext{
${ }^{a}$ Shanghai Key Laboratory of Chemical Biology, East China University of Science and Technology, Shanghai 200237, China. E-mail: xhqian@ecust.edu.cn

${ }^{b}$ Roche Pharmaceutical Research and Early Development, Roche Innovation Center Shanghai, Shanghai 201203, China. E-mail: yimin.hu@roche.com

$\dagger$ Electronic supplementary information (ESI) available. See DOI: $10.1039 / \mathrm{c} 6 \mathrm{ra} 24985 \mathrm{j}$
}

literature, different cyclopropanation strategies can provide access to spirocyclopropyl oxindoles. ${ }^{2}$ However, the potential of applying such strategies in the context of the late-stage functionalization $^{3}$ (LSF) remains to be fully explored. There are limited choices of mild and selective conditions to tolerate aqueous environment, to be compatible with unprotected and sensitive functional groups such as amines, hydroxyl and carboxyl groups, and boronic acids, and to be suitable for functionalization of complex structures. ${ }^{4}$

One common cyclopropanation method involves the use of 1,2-dibromoethane. In general, a strong base, such as $\mathrm{NaH}$ or LiHMDS, is needed for this transformation. ${ }^{5}$ Application of such method often requires protection on oxindole nitrogen as well as other acidic functional groups. With unprotected oxindoles, over-alkylation on the nitrogen is a common side reaction. Over-alkylation can be used as a protection strategy. With unprotected oxindole 7a, Robertson obtained over-alkylated product 8a with excess reagents first. ${ }^{6}$ Subsequent treatment with magnesium achieved debromoethylation to afford cyclopropyl oxindole 9a, with an overall poor yield (Scheme 1). Recently, Marini reported a vinyl selenone-based approach for the synthesis of spirocyclopropyl oxindoles in aqueous sodium hydroxide solution. ${ }^{2 e}$ Limited choices of substitutions on the oxindole were reported. A strong base $(\mathrm{NaOH})$ along with surfactants is necessary for optimal yields.

On the other hand, vinyl sulfonium salts can be easily prepared with robust and safe protocols, and have demonstrated diverse applications in the construction of different carbo- and hetero-cycles. ${ }^{7}$ In 2012 , Lin reported the use of vinyl sulfonium salts, with DBU as the base in dichloromethane, for the cyclopropanation of $\alpha$-amino aryl ketones. ${ }^{8}$ In the case of unprotected oxindoles, due to the similar $\mathrm{p} K_{\mathrm{a}}$ of $\mathrm{C} 3-\mathrm{H}$ and $\mathrm{N}-\mathrm{H}$ ( 18.2), ${ }^{9}$ selective C-3 functionalization could be more challenging than the case of $\alpha$-amino aryl ketones. Indeed simple application of Lin's conditions with oxindole 7a did not produce satisfactory results. An incomplete conversion and more than $50 \%$ of over-alkylated product 10 a were observed. During our optimization, we found that addition of $\mathrm{Zn}(\mathrm{OTf})_{2}$ promoted $\mathrm{C}-3$ 
Previous works:

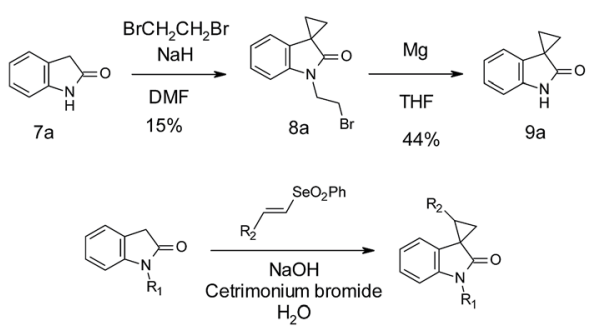

Ref. 6

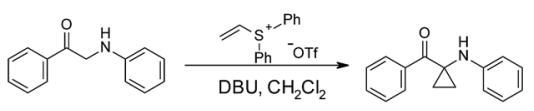

Challenges with unprotected oxindole:

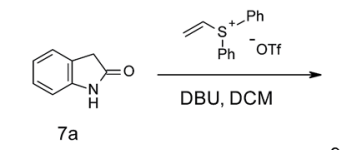

9a: $24 \%$ by LCMS

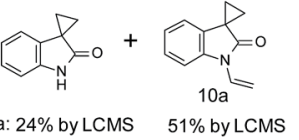

This work:

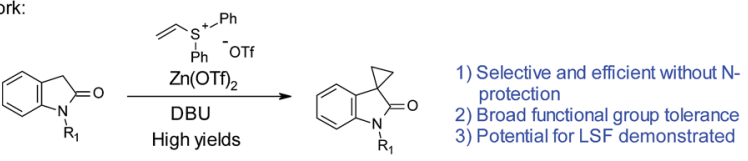

Scheme 1 Cyclopropanation of unprotected oxindoles.

alkylation over $N$-alkylation. Herein, we report an efficient cyclopropanation for both $\mathrm{N}$-nonsubstituted and $\mathrm{N}$-substituted oxindoles with vinyl diphenylsulfonium triflate salt mediated by zinc triflate. The ambient reaction conditions are simple, mild, and devoid of alkali bases. We were pleased to find that this cyclopropanation could proceed efficiently with high yields, tolerating a variety of functional groups such as carboxylic acid, hydroxyl, amine, boronic acid, etc. The utility in LSF has also been demonstrated with three examples.

Optimization efforts with unprotected indole 7a are summarized in Table 1. As stated above, partial conversion and a $32 \%$ isolated yield of product 9a could be obtained by applying previously reported conditions, with DBU as the base and DCM as the solvent (entry 1). Screening of different bases and solvents did not produce any improvement on regioselectivity over $\mathrm{N}$ alkylation (entries 2-5). A marginally improved yield of $38 \%$ was observed with a polar solvent such as DMF (entry 6). To our delight, addition of 2 equivalents of $\mathrm{Mg}(\mathrm{OTf})_{2}$ promoted the C-3 alkylation with a $56 \%$ yield of $9 a$ (entry 7 ). Encouraged by this finding, various metal salts were screened. $\mathrm{Zn}(\mathrm{OTf})_{2}$ and $\mathrm{Ca}(\mathrm{OTf})_{2}$ gave the best yields (entry 8-12). Further refinement of conditions focused on adjusting the amounts and ratio of DBU and $\mathrm{Zn}(\mathrm{OTf})_{2}$ (entries 13-16). We found that reducing the amount of $\mathrm{Zn}(\mathrm{OTf})_{2}$ from 2 to 1 equivalent (entry 15 vs. 12) gave a clean reaction with full conversion. Over $90 \%$ of the desired product $9 a$ was isolated with almost no $\mathrm{N}$-alkylation product observed by LC/ MS. The use of $\mathrm{Zn}(\mathrm{OAc})_{2}$ resulted in poorer yields of 9a. Different from $\mathrm{Zn}(\mathrm{OTf})_{2}$, reducing the equivalents of $\mathrm{Ca}(\mathrm{OTf})_{2}$ from 2 to 1 gave only a $50 \%$ isolated yield (entry $18 v s$. 8).

With the optimized conditions in hand, we then examined the scope of oxindole substrates (Table 2). As shown in Table 2A, reactions of substrates containing electron-rich or electron-
Table 1 Optimization with oxindole $7 a^{a}$

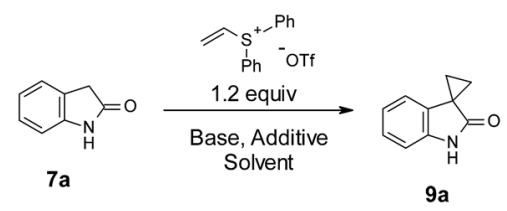

\begin{tabular}{|c|c|c|c|c|}
\hline Entry & Base (equiv.) & Additive (equiv.) & Solvent & Yield (\%) \\
\hline 1 & DBU (3.0) & - & DCM & 32 \\
\hline 2 & TEA (3.0) & - & DCM & 30 \\
\hline 3 & DIPEA (3.0) & - & DCM & 27 \\
\hline 4 & Pyridine (3.0) & - & DCM & 0 \\
\hline 5 & $\mathrm{Cs}_{2} \mathrm{CO}_{3}(3.0)$ & - & DCM & $<5$ \\
\hline 6 & DBU (3.0) & - & DMF & 38 \\
\hline 7 & DBU (3.0) & $\mathrm{Mg}(\mathrm{OTf})_{2}(2.0)$ & DMF & 56 \\
\hline 8 & DBU (3.0) & $\mathrm{Ca}(\mathrm{OTf})_{2}(2.0)$ & DMF & 68 \\
\hline 9 & DBU (3.0) & $\mathrm{Cu}(\mathrm{OTf})_{2}(2.0)$. & DMF & $<5$ \\
\hline 10 & DBU (3.0) & $\operatorname{Ag}(\mathrm{OTf})(2.0)$ & DMF & $<5$ \\
\hline 11 & DBU (3.0) & $\mathrm{CuCl}_{2}(2.0)$ & DMF & 55 \\
\hline 12 & DBU (3.0) & $\mathrm{Zn}(\mathrm{OTf})_{2}(2.0)$ & DMF & 70 \\
\hline 13 & DBU (2.0) & $\mathrm{Zn}(\mathrm{OTf})_{2}$ & DMF & 78 \\
\hline 14 & DBU (4.0) & $\mathrm{Zn}(\mathrm{OTf})_{2}(2.0)$ & DMF & 90 \\
\hline 15 & DBU (3.0) & $\mathrm{Zn}(\mathrm{OTf})_{2}(1.0)$ & DMF & 91 \\
\hline 16 & DBU (3.0) & $\mathrm{Zn}(\mathrm{OTf})_{2}(0.5)$ & DMF & 68 \\
\hline 17 & DBU (3.0) & $\mathrm{Zn}(\mathrm{OAc})_{2}(1.0)$ & DMF & 46 \\
\hline 18 & DBU (3.0) & $\mathrm{Ca}(\mathrm{OTf})_{2}(1.0)$ & DMF & 50 \\
\hline
\end{tabular}

${ }^{a}$ Reaction conditions: $7 \mathrm{a}(0.2 \mathrm{mmol})$, vinyl diphenyl sulfonium triflate $(0.24 \mathrm{mmol})$, with indicated amount of base and additive, $1 \mathrm{~mL}$ solvent, at room temperature $\left(\mathrm{ca} .21{ }^{\circ} \mathrm{C}\right)$, under air, stirring for $4 \mathrm{~h}$. Isolated yields are shown.

withdrawing substituents afforded high yields of desired products. The substitution position of the oxindole had minimal influence on the reaction yields either, with the exception of $\mathbf{7 m}$ and $7 \mathbf{n}$. 1.5 equivalents of $\mathrm{Zn}(\mathrm{OTf})_{2}$ were necessary to obtain full conversion and high yields of $\mathbf{9 m}$ and $\mathbf{9 n}$. A broader substrate scope was demonstrated in Table 2B. Both electron deficient pyridine 90 and electron rich thiophene 9p were obtained in high yields. Remarkably, phenol 7q, boronic ester $\mathbf{7 r}$, and even pyridyl boronic acid 7s, all underwent cyclopropanation to give the corresponding products $\mathbf{9 q} \mathbf{- s}$ in good yields. Cyclopropanation on medicinally relevant and complex compounds was also performed to demonstrate the utility in LSF (Table 2C). For example, cyclopropanation of Ropinirole (1a), a dopamine agonist used in the treatment of Parkinson's disease and restless legs syndrome (RLS), and bearing a basic tertiary amine, proceeded under our standard conditions to form $\mathbf{1 b}$ in $85 \%$ yield. Ziprasidone (2a), an atypical antipsychotic containing a benzisothiazole found in many signal transduction modulators, also underwent a smooth cyclopropanation to give $\mathbf{2 b}$ in $95 \%$ yield. Finally, cyclopropanation of PF562271 (3a), a focal adhesion kinase inhibitor once in early clinical trials for treatment of cancer, with 1 active methylene group and 2 more unprotected $\mathrm{NHs}$ in addition to oxindole $\mathrm{NH}$, reacted well to afford $\mathbf{3 b}$ in $92 \%$ yield. The above results, particularly in Tables $2 \mathrm{~B}$ and C, demonstrated that chemistry described herein can be applicable for late stage cyclopropanation of important building blocks and complex drug-like molecules. 
Table $2 \mathrm{Zn}(\mathrm{OTf})_{2}$-mediated cyclopropanation of oxindoles without $N$-substituents

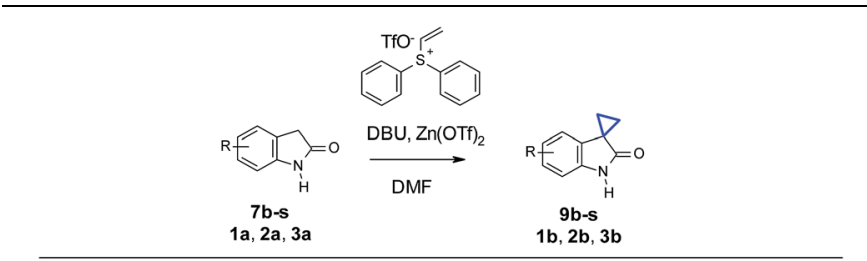

$\mathrm{A}^{a}$

$$
\text { (9., }
$$

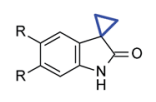

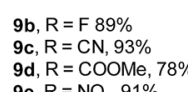$$
9 \mathbf{e}, \mathrm{R}=\mathrm{NO}_{2}, 91 \%
$$

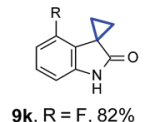

$9 \mathrm{l}, \mathrm{R}=\mathrm{Br}, 85 \%$
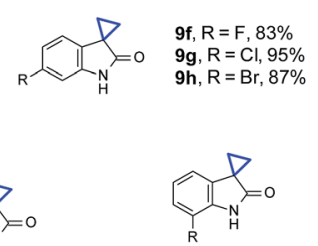

$9 \mathrm{~m}, \mathrm{R}=\mathrm{OMe}, 82 \% \mathrm{~b}$ $9 \mathrm{n}, \mathrm{R}=\mathrm{Cl}, 81 \%^{b}$

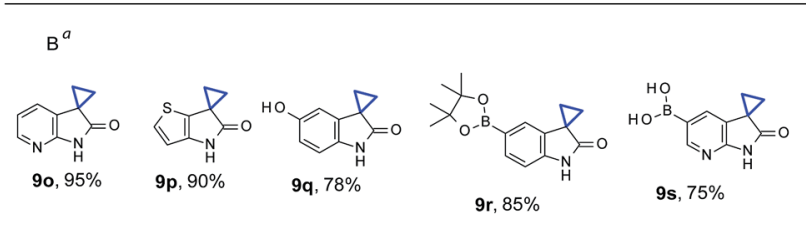

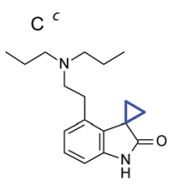

$1 b, 85 \%$

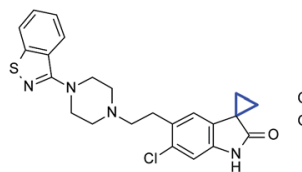

2b, $95 \%$

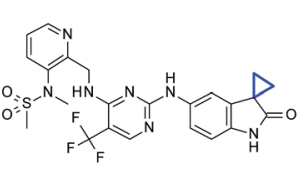

3b, $92 \%$
${ }^{a}$ Reaction conditions for $\mathbf{7 b}-\mathbf{l}$, and $\mathbf{7 0 - \mathbf { s }}$ : oxindole $(0.2 \mathrm{mmol})$, vinyl diphenyl sulfonium triflate $(0.24 \mathrm{mmol}), \mathrm{Zn}(\mathrm{OTf})_{2}(0.2 \mathrm{mmol})$, DBU $(0.6 \mathrm{mmol})$, in $1 \mathrm{~mL} \mathrm{DMF}$, at room temperature $\left(c a .21^{\circ} \mathrm{C}\right)$, under air, stirring for 4 h. ${ }^{b}$ For $\mathbf{7 m}$ and $\mathbf{7 n}$ : condition similar to $7 \mathbf{b}-\mathbf{l}$ with 0.3 mmol of $\mathrm{Zn}(\mathrm{OTf})_{2}$ being used. ${ }^{c}$ For 1a, 2a, and 3a: conditions similar to $7 \mathbf{b}-\mathbf{l}$ with reaction time extended to $12 \mathrm{~h}$. Isolated yields for all substrates described in the figure.

In addition to $\mathrm{N}$-nonsubstituted oxindoles, we also examined cyclopropanation with $\mathrm{N}$-substitued oxindole substrates (Table 3). Addition of $\mathrm{Zn}(\mathrm{OTf})_{2}$ is not necessary for high yields, due to the presence of " $N$-protecting" substitutions $(\mathbf{1 1 a}-\mathbf{c})$. Results are comparable with or without $\mathrm{Zn}(\mathrm{OTf})_{2}$ (11a and 11d). In the case of Boc-protected oxindole 11b, the yield with $\mathrm{Zn}(\mathrm{OTf})_{2}$ was lower than the conditions without $\mathrm{Zn}(\mathrm{OTf})_{2}$ (50\% vs. $85 \%$ ). About $30 \%$ of de-Boc product was observed, presumably due to the Lewis acidity of $\mathrm{Zn}(\mathrm{OTf})_{2}$. Functional groups such as carboxyl acid (12d) and primary amine (12e) were well tolerated for cyclopropanation. No $O$-alkylation by-products were observed in the case of carboxyl acid (11d). For unprotected aniline containing substrate 11e, the reaction was sluggish under standard conditions with $\mathrm{Zn}(\mathrm{OTf})_{2}$. Partial conversion and $\mathrm{N}$-alkylation were observed with only $42 \%$ product (12e) isolated. In the absence of $\mathrm{Zn}(\mathrm{OTf})_{2}$, at higher temperature $\left(130{ }^{\circ} \mathrm{C}\right)$ under microwave for 1 hour, 11e did undergo cyclopropanation smoothly with full conversion, leading to $12 \mathrm{e}$ in $82 \%$ yield. Only minor amount ( $<10 \%$ by LC/MS) of the $N$-alkylation byproduct was observed.
Table 3 Cyclopropanation of oxindoles with $N$-substituents ${ }^{a}$

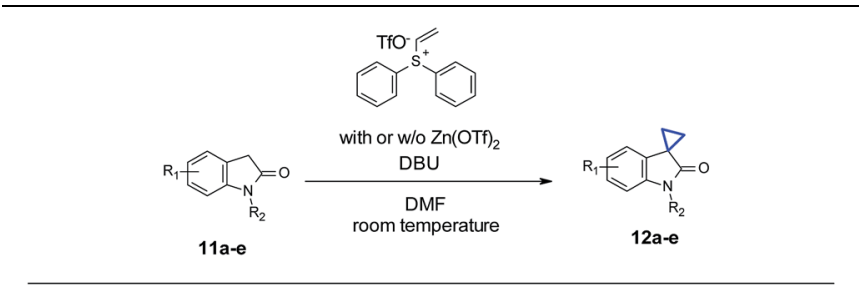

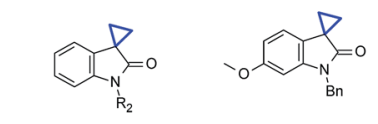

12a, $R_{2}=\mathrm{Me}, 97 \%^{a}(98 \%)^{b} \quad 12 \mathrm{c}, 87 \%^{a}$ $12 b, R_{2}=\operatorname{Boc}, 85 \%^{a}(50 \%)^{b}$

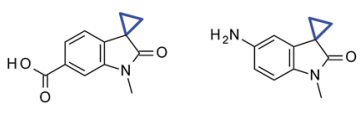

$12 \mathrm{~d}, 95 \%^{a}(97 \%)^{b} \quad 12 \mathrm{e}, 82 \%^{c}(42 \%)^{b}$
${ }^{a}$ Reaction conditions: oxindole $(0.2 \mathrm{mmol})$, vinyl diphenyl sulfonium triflate $(0.24 \mathrm{mmol})$, DBU $(0.6 \mathrm{mmol})$, in $1 \mathrm{~mL} \mathrm{DMF}$, at room temperature $\left(21{ }^{\circ} \mathrm{C}\right)$, under air, stirring for $12 \mathrm{~h}$. ${ }^{b}$ Yields in parentheses correspond to similar conditions with $0.2 \mathrm{mmol}$ of $\mathrm{Zn}(\mathrm{OTf})_{2}$ being used. ${ }^{c}$ Reaction conditions: oxindole $(0.2 \mathrm{mmol})$, vinyl diphenyl sulfonium triflate $(0.21 \mathrm{mmol})$, in $1 \mathrm{~mL} \mathrm{DMSO}, 130{ }^{\circ} \mathrm{C}$, microwave, $1 \mathrm{~h}$. Isolated yields for all substrates described in the table.

To our delight, for substrates with sufficient aqueous solubility, cyclopropanation with vinyl diphenyl sulfonium triflate also proceeded well at room temperature (Scheme 2). Different from reported vinyl selenone chemistry, ${ }^{2 e}$ neither a strong base $(\mathrm{NaOH})$ nor a surfactant (cetyltrimethyl ammonium bromide) was needed in our case. Oxindole 11d demonstrated adequate solubility with DBU in water and reacted with vinyl diphenyl sulfonium triflate smoothly to afford 12d in 93\% yield. For substrates with less optimal aqueous solubility, such as 11a, a co-solvent system was sufficient to obtain a satisfactory yield (90\% for 12a).

A series of experiments were performed to understand the effect of $\mathrm{Zn}(\mathrm{OTf})_{2}$. We initially thought that $\mathrm{N}$-alkylation could be reversible under $\mathrm{Zn}(\mathrm{OTf})_{2}$-mediated conditions, while the CC bond formation may be irreversible. Furthermore, the $\mathrm{N}$ alkylation product could potentially be used to provide a "vinyl intermediate" for another desirable cyclopropanation in the

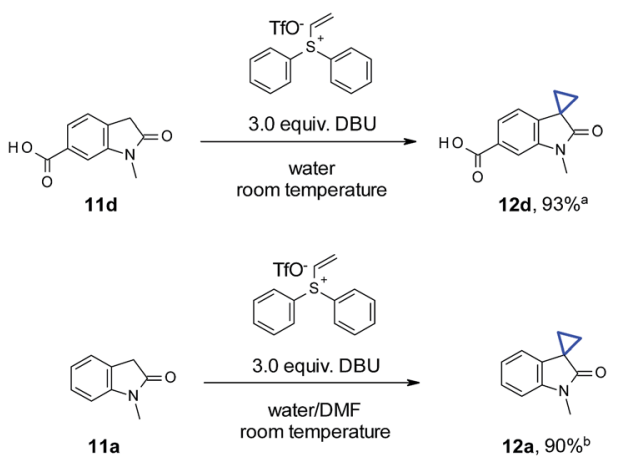

Scheme 2 The use of water as the solvent/co-solvent ${ }^{a}$ reaction conditions: oxindole $(0.2 \mathrm{mmol})$, vinyl diphenyl sulfonium triflate $(0.24$ $\mathrm{mmol}), \mathrm{DBU}(0.6 \mathrm{mmol})$, in $1 \mathrm{~mL} \mathrm{H}_{2} \mathrm{O}$, room temperature $\left(21^{\circ} \mathrm{C}\right)$, stirring for $4 \mathrm{~h}$. Isolated yield; ${ }^{b}$ conditions similar to above with $0.65 \mathrm{~mL}$ $\mathrm{H}_{2} \mathrm{O}$ and $0.35 \mathrm{~mL}$ DMF as co-solvent. Isolated yield. 
presence of $\mathrm{Zn}(\mathrm{OTf})_{2}$. In order to test this hypothesis, as shown in Scheme 3A, with 3.0 equivalents of DBU and 1.0 equivalent of vinyl diphenyl sulfonium triflate, oxindole $7 \mathbf{a}$ underwent a partial conversion to 8a along with significant amount of $\mathrm{N}$ alkylated 10a (cannot be isolated), as suggested by the LC/MS analysis. We then added 1.0 equivalent of $\mathrm{Zn}(\mathrm{OTf})_{2}$ and a different oxindole 11a, in which the $N$-alkylation was impossible to occur. No cyclopropanation product 12 a could be detected up to 12 hours. In Scheme 3B, a similar reaction with oxindole 7a was conducted with $\mathrm{Et}_{3} \mathrm{~N}$ as the base. Interestingly, a different $N$-alkylation product 13a was observed, and 13a could be even isolated. The reaction of isolated 13a in the presence of 1.0 equivalent of oxindole 11a, 1 equivalent of $\mathrm{Zn}(\mathrm{OTf})_{2}$, and 3.0 equivalents of $\mathrm{DBU}$ in DMF gave no spirocyclopropyl oxindole 12a. Conversion of $13 a$ to $10 a$ was detected by LC/MS. The above results indicated that there was no transfer of vinyl group (10a) or vinyl group precursor (13a) to 11a. This suggested that the role of $\mathrm{Zn}(\mathrm{OTf})_{2}$ was not to promote reversibility of $\mathrm{N}$-alkylation, thereby offering a vinyl intermediate for subsequent cyclopropanation reaction leading to more desired cyclopropyl products.

In Scheme 3C, we studied the reaction in more detail with oxindole $\mathbf{7 n}$. Substitution close to the oxindole nitrogen showed negative influence on the effect of $\mathrm{Zn}(\mathrm{OTf})_{2}$. For example, 1.5 equivalents of $\mathrm{Zn}(\mathrm{OTf})_{2}$ were necessary to block the $\mathrm{N}$-alkylation, suggesting that the adjacent $\mathrm{Cl}$ could hinder the complexation of nitrogen with $\mathrm{Zn}$, which in turn rendered the
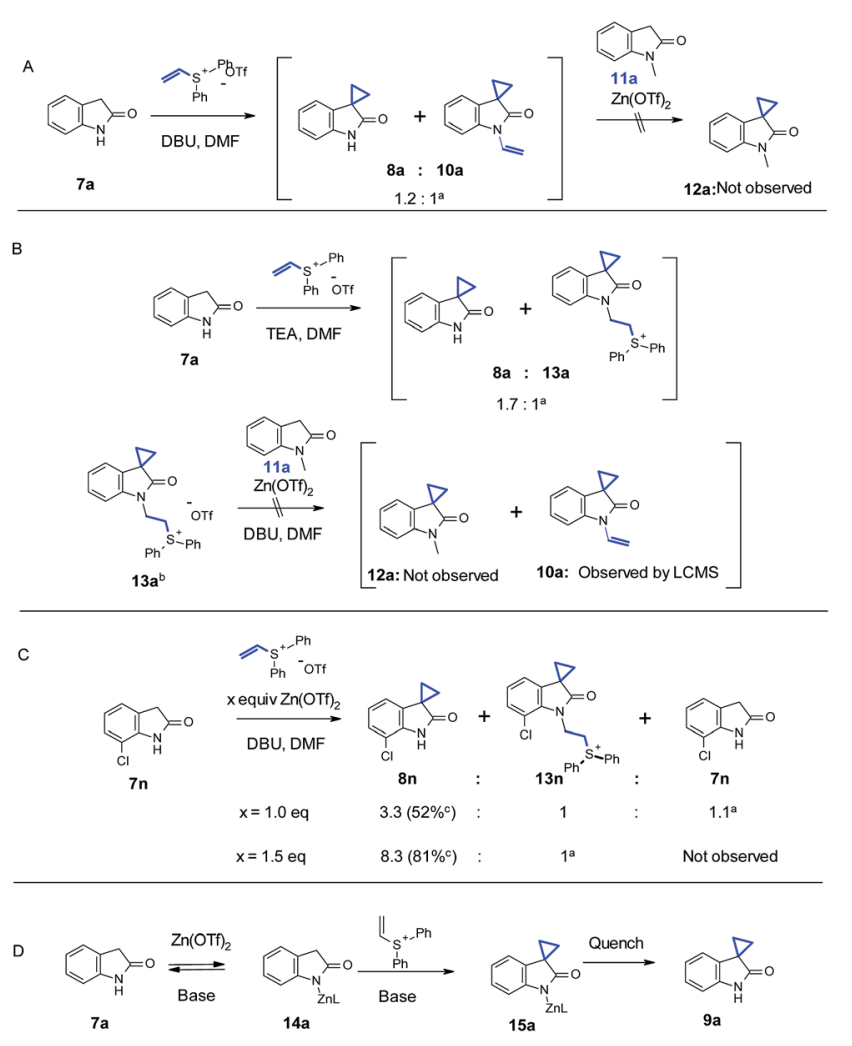

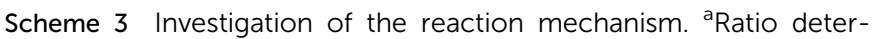
mined by LC/MS; ${ }^{b}$ isolated by crystalization; ${ }^{c}$ isolated by silica gel chromatography. undesired $N$-alkylation product. A similar result was also observed with $\mathbf{7 m}$. Thus we propose that the $\mathrm{Zn}$ coordination to the oxindole nitrogen could account for the observed regioselectivity under our Zn-mediated conditions. Furthermore, the proposed zinc complex 14a could enhance the acidity of the benzylic proton which is adjacent to the lactam. Therefore, weaker bases could be applied to significantly boost functional group compatibility. As shown in Scheme 3D, the $\mathrm{Zn}$ complexation on the nitrogen could directly block the $N$-alkylation pathway. Results with oxindole 11e in Table 3 under the Znmedicated conditions also suggest that an extra coordinating group, such as the amino group of aniline, could presumably complete with the complexation of $\mathrm{Zn}(\mathrm{OTf})_{2}$ to the oxindole nitrogen thereby slowing down the reaction. This observation further corroborates the depicted mechanism in Scheme 3D.

In summary, we have developed an efficient cyclopropanation method for both N-nonsubstituted and $\mathrm{N}$ substituted oxindoles with the commercially readily available vinyl diphenylsulfonium triflate. The conditions are convenient and mild, with no requirement of inert atmosphere or alkalis bases. A broad reaction scope is observed, with applications on late stage cyclopropanation of three medicinally interesting compounds. We envision that this synthetic methodology could be widely adopted by the medicinal chemistry community. Particularly, the employment of zinc triflate can block the $\mathrm{N}$ alkylation byproduct using N-nonsubstituted oxindoles. It is conceivable that such concept could be applied in other cases where regioselectivity issue exists.

\section{Acknowledgements}

We thank Professor Guangbin Dong (University of Chicago) and Professor Xiaoguang Lei (Peking University) for helpful discussions. We also thank Mr Sheng Zhong (Roche Innovation Center Shanghai) for mass spectrometry.

\section{Notes and references}

1 (a) B. Yu, D.-Q. Yu and H.-M. Liu, Eur. J. Med. Chem., 2015, 97, 673; (b) N. Ye, H. Chen, E. A. Wold, P.-Y. Shi and J. Zhou, J. Infect. Dis., 2016, 2, 382.

2 (a) R. Zhou, C. Yang, Y. Liu, R. Li and Z. He, J. Org. Chem., 2014, 79, 10709; (b) Z.-Y. Cao and J. Zhou, Org. Chem. Front., 2015, 2, 849; J.-H. Li, T.-F. Feng and D.-M. Du, J. Org. Chem., 2015, 80, 11369. (c) M.-H. Shen, K. Xu, C.-H. Sun and H.-D. Xu, Org. Biomol. Chem., 2016, 14, 1272; (d) J. Guo, Y. Liu, X. Li, X. Liu, L. Lin and X. Feng, Chem. Sci., 2016, 7, 2717; (e) M. Palomba, L. Rossi, L. Sancineto, E. Tramontano, A. Corona, L. Bagnoli, C. Santi, C. Pannecouque, O. Tabarrini and F. Marini, Org. Biomol. Chem., 2016, 14, 2015; (f) P. B. Sampson, Y. Liu, N. K. Patel, M. Feher, B. Forrest, S.-W. Li, L. Edwards, R. Laufer, Y. Lang, F. Ban, D. E. Awrey, G. Mao, O. Plotnikova, G. Leung, R. Hodgson, J. Mason, X. Wei, R. Kiarash, E. Green, W. Qiu, N. Y. Chirgadze, T. W. Mak, G. Pan and H. W. Pauls, J. Med. Chem., 2015, 58, 130. 
3 (a) A. Sharma and J. F. Hartwig, Nature, 2015, 517, 600; (b) X. Huang, T. M. Bergsten and J. T. Groves, J. Am. Chem. Soc., 2015, 137, 5300; (c) S. Song, X. Sun, X. Li, Y. Yuan and N. Jiao, Org. Lett., 2015, 17, 2886; (d) K. J. Frankowski, R. Liu, G. L. Milligan, K. D. Moeller and J. Aubé, Angew. Chem., Int. Ed., 2015, 54, 10555; (e) F. Shen, S. Tyagarajan, D. Perera, S. W. Krska, P. E. Maligres, M. R. Smith III and R. E. Maleczka Jr, Org. Lett., 2016, 18, 1554.

4 T. Cernak, K. D. Dykstra, S. Tyagarajan, P. Vachal and S. W. Krska, Chem. Soc. Rev., 2016, 45, 546.

5 (a) A. Lerchner and E. M. Carreira, J. Am. Chem. Soc., 2002, 124, 14826; (b) J. X. Qiao, T. C. Wang, R. Ruel, C. Thibeault, A. L'Heureux, W. A. Schumacher, S. A. Spronk, S. Hiebert, G. Bouthillier, J. Lloyd, Z. Pi, D. M. Schnur, L. M. Abell,
J. Hua, L. A. Price, E. Liu, Q. Wu, T. E. Steinbacher, J. S. Bostwick, M. Chang, J. Zheng, Q. Gao, B. Ma, P. A. McDonnell, C. S. Huang, R. Rehfuss, R. R. Wexler and P. Y. S. Lam, J. Med. Chem., 2013, 56, 9275.

6 D. W. Robertson, J. H. Krushinski, G. D. Pollock, H. Wilson, R. F. Kauffman and J. S. Hayes, J. Med. Chem., 1987, 30, 824. 7 (a) J. Gosselck, L. Béress and H. Schenk, Angew. Chem., Int. $E d$., 1966, 5, 596; (b) M. G. Unthank, N. Hussain and V. K. Aggarwal, Angew. Chem., Int. Ed., 2006, 45, 7066; (c) B. Unthank, B. Tavassoli and V. K. Aggarwal, Org. Lett., 2008, 10, 1501.

8 Z. Mao, H. Qu, Y. Zhao and X. Lin, Chem. Commun., 2012, 48, 9927.

9 F. G. Bordwell and H. E. Fried, J. Org. Chem., 1991, 56, 4218. 